\title{
COMPUTATIONAL FLUID DYNAMIC ANALYSIS OF HIGHWAY BRIDGES EXPOSED TO HURRICANE WAVES
}

\author{
M. Bozorgnia ${ }^{1}$, Jiin-Jen Lee ${ }^{1}$
}

In present paper, numerical code STAR CCM+ by CD-adapco which works based on compressible two-phase Navier Stokes equations is used to evaluate hydrodynamic forces exerted on prototype of I10 Bridge over Escambia Bay which was extensively damaged during Hurricane Ivan. Volume of Fluid (VOF) is used to capture dynamic free surface which is well suited for simulating complex discontinuous free surface associated with wave-deck interactions. 2D and 3D models were setup and properly configured. Simulations were conducted on High performance Computing and Communication Center (HPCC) at University of Southern California. Simulation results are compared to experimental data available from Hinsdale Wave Laboratory at Oregon State University. Comparison of experimental data to simulation results show the importance of proper mesh size and time step choice on accuracy of horizontal and vertical hydrodynamic force predictions applied to bridge superstructure.

Keywords: Wave Structure Interaction; Computational Fluid Dynamic (CFD), Escambia Bay Bridge; Hurricane Ivan.

\section{INTRODUCTION}

Bridges are vital components of transportation system. There are more than 60,000 miles of highway in US exposed to coastal tides, waves and currents. According to NYCDOT (New York State Department of Transportation) between 1996 and 2005, there were more than 500,000 bridges over waterway out of which 1500 bridges failed within last 40 years. About 60 percent of these bridges failed due to hydraulic related reasons (NYCDOT 2005).

Figure 1 shows I10 bridge in Bay St. Louis which was heavily damaged during Hurricane Katrina in 2005. The wave height is shown to be about 9 meter versus the bridge deck elevation which was about $2.5 \mathrm{~m}$. Figure 2 shows the Escambia Bay bridge which was heavily damaged during hurricane Ivan in 2004. The storm surge associated with Hurricane Ivan (September 16, 2004) knocked 58 spans off the eastbound and westbound bridges, the surge also misaligned another 66 spans, causing the bridge to be closed to traffic in both directions.

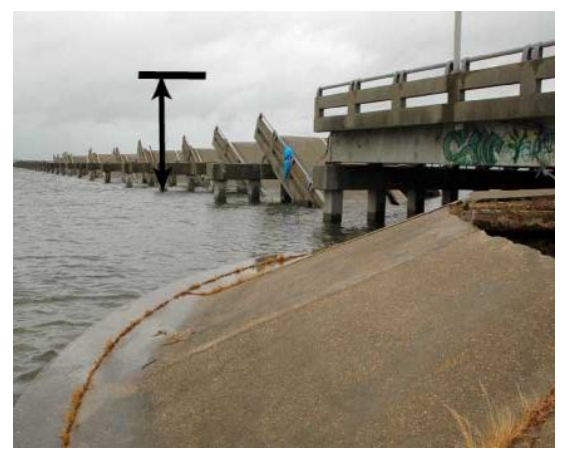

Figure 1. I10 bridge in Bay St. Louis damaged during Hurricane Katrina

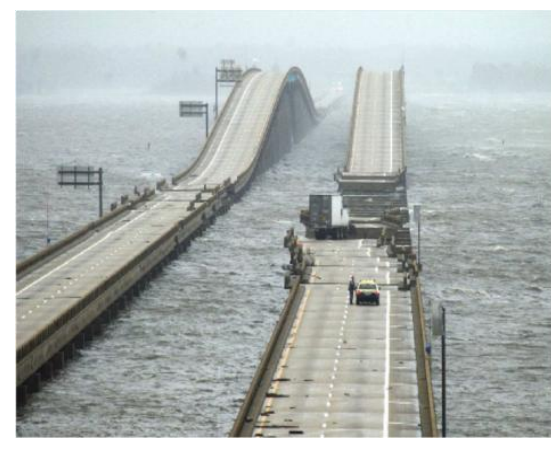

Figure 2. Escambia Bay Bridge damaged during Hurricane Ivan

The objective of this paper is to validate a three dimensional compressible numerical wave load model based on Navier Stokes type equation by comparing simulated hydrodynamic forces applied to bridge superstructure to experimental data available from Hinsdale wave laboratory in Oregon State University.

In the following sections, the numerical wave load model is described and validated by comparison to experimental data. Several mesh size and time steps are investigated to find the most appropriate mesh size and time step for the wave-bridge interaction problem. All simulations are conducted on High performance Computing and Communication Center (HPCC) at University of Southern California. For some cases due to large number of mesh and small time step used in the simulation, 20 second wave-bridge interaction took up to 7 days running on about 200 CPUs. The nodes used for these simulations were Intel xenon $(2.5 \mathrm{GHz})$.

${ }^{1}$ Sonny Astani Department of Civil \& Environmental Engineering, University of Southern California, 3620 S. Vermont Ave., Los Angeles, CA, 90089-2531, USA 


\section{LITRETURE REVIEW OF WAVE INTERACTING WITH BRIDGE DECK}

After Hurricane Katrina since numerous bridge superstructures were damaged, several attempts have been made to predict hydrodynamic forces on bridge superstructure.

Douglass et al. (2006) reviewed existing literature related to Hurricane wave forces on highway bridge superstructures. They concluded that existing methods to evaluate wave loads on highway bridge geometries were inadequate and would not accurately predict the observed damage during Hurricane Ivan and Katrina. Douglass et al. (2006) conducted laboratory experiments and based on experimental data, proposed a new empirical equation for estimating wave loads on bridge decks. Cuomo et al. (2007) measured wave forces and pressure on a 1:25 scale wooden deck with cross and longitudinal down-standing beams. The study showed that hydrodynamic forces depend on wave height, the clearance between the super structure and the still water level (SWL).

The American Association of State Highway and Transportation Officials (AASHTO) have developed a series of equations to calculate design loads on coastal bridges due to waves. These equations are parameterization of a physical-based model derived from Kaplan's equations of wave forces originally developed for offshore oil platforms. The equations account for the bridge span design (slab vs. girder), as well as the type of girders used. The geometry of the bridge span is also considered, including girder depth, span width, and rail height. These equations also account for the effect of trapped air between girders through a trapped air factor (TAF) which is calculated and applied to the quasi steady vertical forces. The recommended application of the TAF allows designers to calculate a range of quasi-steady vertical forces, based on a minimum and maximum TAF.

In 2008 Cox et al. in O.H. Hinsdale Wave Research Laboratory performed large scale experiment on a 1:5 scale, reinforced concrete model of the I-10 Bridge over Escambia Bay, Florida that failed during Hurricane Ivan In 2004. The unique feature of this experiment beside its large scale was the ability of experimental setup to measure structural response directly. The roller and rail system also allowed the specimen to move freely along the axis of wave propagation to simulate the dynamic response of the structure. The data obtained from these experiments were then analyzed to study the relative importance of the impulse load versus the sustained wave load. The experimental data also compared to the wave forces obtained using the latest AASHTO guidelines. It has been determined that the AASHTO formulas do a good job of predicting horizontal forces and can predict the range of vertical forces applied to bridge superstructure depending on the trapped air factor used in the formula.

Few research studies on numerical modeling of wave forces on bridge decks exists in published literature due to expensive cost of numerical simulation. Only with recent advances in computer hardware and availability of high performance computing such simulations became possible. Numerical modeling of wave loads on a full scale bridge deck using the actual deck geometry is a very useful supplementary approach for estimating wave loads.

Huang et al. (2008) did numerical modeling of dynamic wave force acting on the Escambia Bay Bridge deck which was extensively damaged during Hurricane Ivan. They first validated their numerical model by comparing the uplift forces on a simple flat plate to experiments conducted by French (1969) at California Institute of technology. Then they applied the validated model to Escambia Bay Bridge and calculated the wave uplift and impact forces applied to bridge superstructure. $\mathrm{He}$ showed that in Hurricane Ivan, the maximum uplift wave forces were larger than the weight of a simply supported bridge deck, causing direct damage to the bridge deck. He also made comparison of numerical modeling results to maximum wave forces obtained from empirical equations. He concluded that although empirical equations can provide a rapid estimate of maximum wave forces for preliminary risk analysis, numerical modeling is needed to produce details of time series dynamic wave forces to support coastal hazard assessment and bridge designs.

Bozorgnia et al. (2010) conducted numerical simulation of interaction of a solitary wave with the I10 Bridge across Mobil Bay in Alabama which was extensively damaged during Hurricane Katrina. They also validated the numerical model by comparison of the simulated hydrodynamic forces applied to a simple flat plate to experimental data available from French (1969). They demonstrated that the force time history of a solitary wave interacting with the bridge superstructure consisted of a short duration impulsive load followed by quasi steady positive and quasi-steady negative loads. They also quantified the role of entrapped air by allowing the air to vent out through vent holes in bridge deck. They showed that airvents could be used as an effective retrofitting option for reducing vertical hydrodynamic forces applied to bridge superstructure.

None of the numerical models above were validated for interaction of wave with bridge superstructure. The wave-bridge interaction problem is different from interaction of wave with a simple flat plate because of the complex geometry of bridge superstructure. Specific geometry of bridge 
superstructure allows the air to get trapped and compressed under the bridge superstructure between bridge girders and diaphragms while the wave interacts with bridge superstructure. In several incidents in the past, the air entrapment under the bridge super structure during Hurricane was determined to be the main cause of bridge failure. Therefore, validation of a model capable of accurately modeling the complex wave-bridge interaction by considering the effect of air entrapment under the bridge superstructure is necessary.

\section{NUMERICAL MODEL}

In this section basic flow equations are presented. Equations 1 and 2 show the integral form of Navier-Stokes equations.

$$
\begin{gathered}
\frac{d}{d t} \int_{V} \rho d V+\int_{S} \rho\left(\mathrm{v}-\mathrm{v}_{g}\right) \cdot d a=0 \\
\frac{d}{d t} \int_{V} \rho \mathrm{v} d V+\int_{S} \rho \mathrm{v} \otimes\left(\mathrm{v}-\mathrm{v}_{g}\right) \cdot d a=\int_{S}(T-p I) \cdot d a+\int_{V} \rho b d V
\end{gathered}
$$

In these equations, $\rho$ is the fluid density; $V$ is the control volume bounded by a closed surface $S$. v is the fluid velocity vector. $\mathrm{v}_{g}$ is the velocity of the control volume surface, $t$ is time, $p$ is pressure, $b$ is the body force vector, $a$ is face area vector normal to $S$ and directed outwards, and $T$ is viscous stress tensor. In this specific problem of wave interacting with bridge superstructure, since we are dealing with a large body of water interacting with bridge superstructure in a very short time period and we are only concerned about the total forces applied to the bridge superstructure, the importance of viscous term in the above equation is negligible compared to inertia term. Therefore fluid viscosity was neglected in all simulations.

Finite Volume Method (FVM) is used to solve above governing equations numerically. In the finite volume method, the solution domain is subdivided into a finite number of small control volumes, corresponding to the cells of a computational grid. Discrete versions of the integral form of the NavierStokes equations are applied to each control volume. The result is a set of linear algebraic equations, with the total number of unknowns in each equation system corresponding to the number of cells in the grid. (If the equations are non-linear, iterative techniques that rely on suitable linearization strategies must be employed.) The resulting linear equations are then solved with an algebraic multigrid solver. The coupled system of equations is efficiently solved in a segregated manner which means when solved for each variable, other variables are treated as known. Details about the discretization techniques and segregated flow model used can be found in the large body of work by Ferziger and Peric (1996) and STAR CCM+ documentation.

\section{INTERFACE-CAPTURING METHOD}

To capture interface between air and water in the simulation domain, STAR CCM+ uses a variation of VOF method originally proposed by Hirt et al. In addition to the conservation equations for mass and momentum, another equation is solved for volume fraction $\mathrm{c}$ which evolves based on the following transport equation:

$$
\frac{d}{d t} \int_{V} c d V+\int_{S} c\left(\mathrm{v}-\mathrm{v}_{b}\right) \cdot d a=0
$$

In VOF method both fluids are treated as a single effective fluid, whose properties vary in space according to the volume fraction of each phase, i.e.:

$$
\rho=\rho_{1} c+\rho_{2}(1-c) \quad \mu=\mu_{1} c+\mu_{2}(1-c)
$$

Where subscripts 1 and 2 denote the two fluids (e.g. liquid and gas) and for control volumes filled with water $c=1$ and for control volumes filled with air $c=0$. If one $\mathrm{CV}$ is partially filled with one and partially filled with other fluid (i.e. $0 \leq c \leq 1$ ), it is assumed that both fluids have the same velocity and pressure. The discretization of transport equation (3) requires special care. This is due to the fact that $\mathrm{c}$ must be bound by zero and unity and the region in which the cells are only partially filled should be as small as possible. In this research air is assumed to be compressible and water considered 
incompressible. Therefore in each solution time step density is adjusted using a new value of pressure following ideal gas law which relates density of air to its pressure at each time step.

\section{APPLICATION OF NUMERICAL MODEL TO WAVE-BRIDGE INTERACTION PROBLEM}

Numerical model explained in previous section is used to investigate hydrodynamic forces applied to a 1:5 scale model of Escambia Bay Bridge which was damaged during Hurricane Ivan. This model bridge was set up in O.H. Hinsdale Wave Research Laboratory at Oregon State University. Figure 3 shows overall dimensions of the wave flume, location of the test frame with the specimen and the dimensions of the test specimen and reaction frame. The test specimen and reaction frame system is shown in more detail in figure 4.

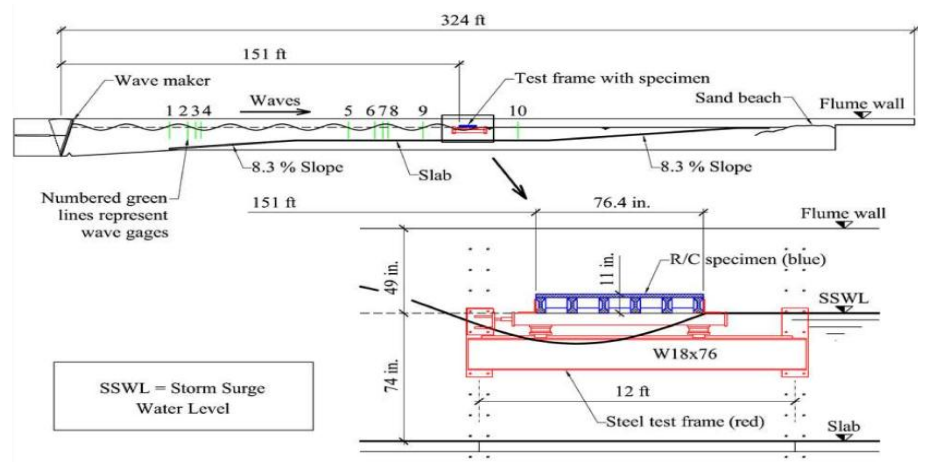

Figure 3. Elevation view of wave flume with experimental setup (Thomas Schumacher, Oregon State University)

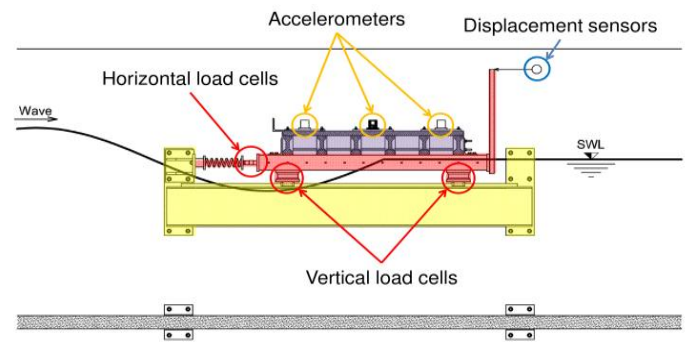

Figure 4. Elevation view of test specimen and reaction frame. Distances are in $\mathbf{m}$ (ft) (Thomas Schumacher, Oregon State University)

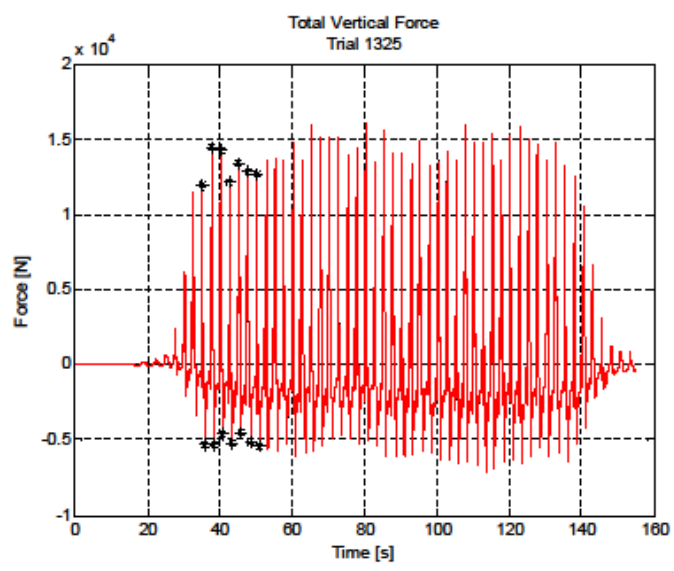

Figure 5. Time series of total vertical force for regular wave trial 1325 in experiment. Markers indicate data used to compute mean positive and negative peak forces (Bradner et al.) 


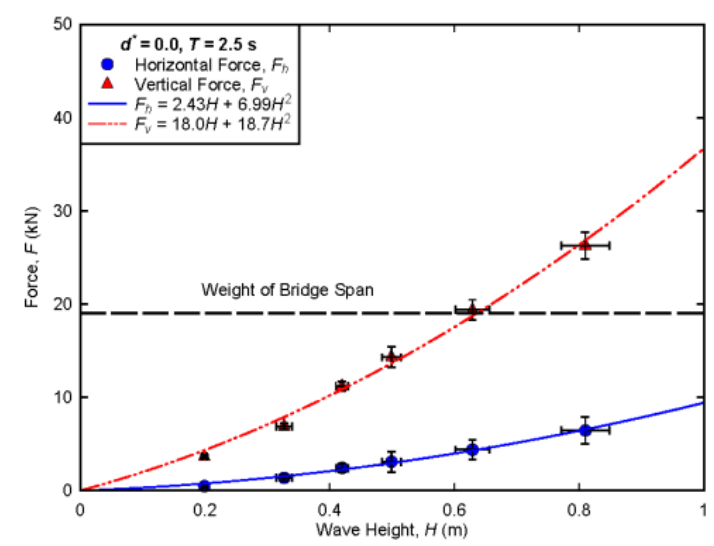

Figure 6. Measured forces in experiment for regular wave trials for $d^{*}=0, T=2.5 s$ (Bradner et al.)

Figure 5 shows the time series of total vertical force measured for wave trial of 1325 for wave height of $\mathrm{H}=0.54 \mathrm{~m}$ and wave period of $\mathrm{T}=2.5 \mathrm{~s}$. Figure 6 shows the total horizontal and vertical forces applied to bridge superstructure for wave trial of $1325\left(\mathrm{~T}=2.5 \mathrm{~s}, \mathrm{~d}^{*}=0\right)$ for different wave heights. $\mathrm{d}^{*}$ is the distance between undisturbed free surface of water and the bottom of bridge girder. In figure 6, each point is the average of the few peaks in the force time history as the wave interacts with the bridge superstructure as shown in figure 5 with black markers. Experiment was conducted for various values of clearance $\left(\mathrm{d}^{*}\right)$ and wave period $(\mathrm{T})$. However the most accurate results according to Bradner et al. was obtained for $\mathrm{d}^{*}=0$ and $\mathrm{T}=2.5 \mathrm{~s}$. Hence we conducted all our simulation cases for the condition of $\mathrm{d}^{*}=0$ and $\mathrm{T}=2.5 \mathrm{~s}$. The water depth for all simulation cases was kept constant at $1.85 \mathrm{~m}$. Figure 6 shows the simulation domain along with boundary conditions used in the $2 \mathrm{D}$ model. The simulations were run for 20 seconds and the average of the peak of the forces in simulation for each wave height is compared with the data available from experiment (figure 6). In choosing the dimensions of simulation domain it is important to consider enough distance between bridge superstructure and velocity inlet and bridge superstructure and pressure outlet so that in 20 seconds of simulation time, reflected wave from pressure outlet boundary do not interfere with the upcoming wave around bridge superstructure. Also the reflected wave from bridge superstructure should not reach the velocity inlet because it will significantly influence simulation results.

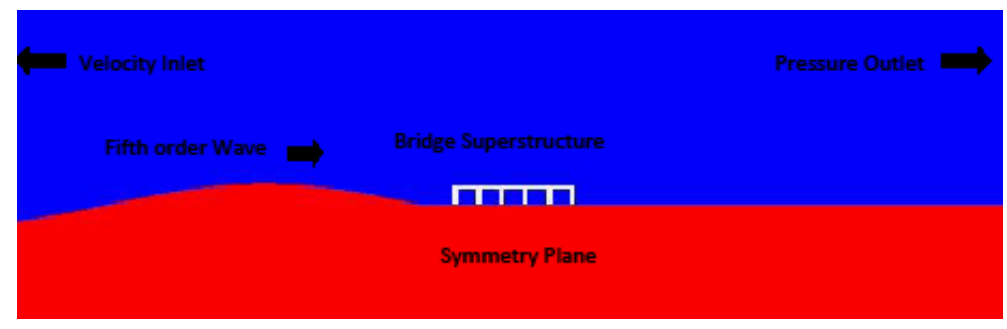

Figure 7. Boundary conditions used in 2D simulations

Since the simulation domain is relatively big and requires fine mesh, mesh optimization becomes important. The best mesh configuration for the problem of this size with current computer resources is shown in figure 8 . The cells are arranged fully orthogonal. Unstructured grid generation is used to save computational time with a very fine mesh around the bridge structure and coarse mesh in deep water and in air region. The grid around the bridge deck is generated more densely because flow pattern is more complex. In addition, $8 \mathrm{~m}$ passed the bridge structure the mesh is coarsened to save the number of mesh used in the simulation domain. Special care need to be used in coarsening mesh in free surface to avoid excessive wave dissipation. If the mesh in free surface is not fine enough, it will damp out significantly before reaching the bridge superstructure. Also in mesh transition regions we have to make sure they are not abrupt changes in mesh size. Not only abrupt changes in the mesh size cause 
numerical error, it also causes the wave to reflect backwards if its dimension is changed abruptly. Mesh sizes and time steps investigated are shown in table 1.

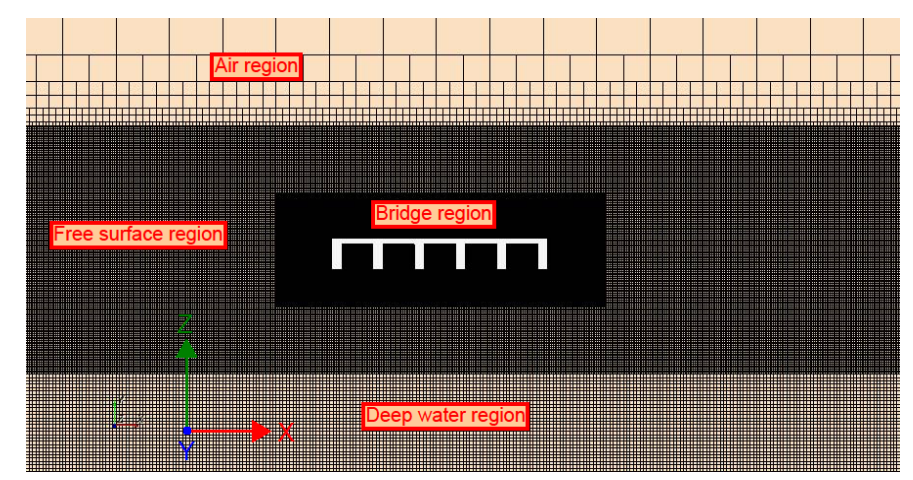

Figure 8. Different mesh regions in simulation domain

\begin{tabular}{|c|c|c|c|c|c|c|c|c|c|}
\hline \multirow{3}{*}{ Test } & \multirow{3}{*}{ Model } & \multirow{3}{*}{$\Delta \mathrm{t}(\mathrm{s})$} & \multicolumn{6}{|c|}{ Mesh size $(\mathrm{cm})$} & \multirow{3}{*}{$\begin{array}{c}\text { Total } \\
\text { number of } \\
\text { cells }\end{array}$} \\
\hline & & & \multicolumn{2}{|c|}{ Bridge } & \multicolumn{2}{|c|}{ Free surface } & \multicolumn{2}{|c|}{ Deep water } & \\
\hline & & & $\Delta \mathrm{x}$ & $\Delta y$ & $\Delta x$ & $\Delta y$ & $\Delta \mathrm{x}$ & $\Delta y$ & \\
\hline 1 & $2 \mathrm{D}$ & 0.02 & 0.72 & N/A & 2.4 & N/A & 4.8 & N/A & 733,537 \\
\hline 2 & $2 \mathrm{D}$ & 0.004 & 1.44 & N/A & 2.4 & N/A & 4.8 & N/A & 358,659 \\
\hline 3 & $3 D$ & 0.02 & 1.44 & 5.76 & 4.8 & 11.52 & 9.6 & 23.04 & $2,834,678$ \\
\hline 4 & $3 D$ & 0.004 & 1.44 & 5.76 & 4.8 & 11.52 & 9.6 & 23.04 & $2,834,678$ \\
\hline 5 & $3 D$ & 0.004 & 0.72 & 2.88 & 2.4 & 11.52 & 9.6 & 23.04 & $11,483,096$ \\
\hline
\end{tabular}

Table 1. Mesh sizes and time steps investigated for 2D and 3D model

In all simulation cases (2D and 3D), mesh used in $\mathrm{x}$ and $\mathrm{z}$ direction are the same size. In general it is recommended to refine the mesh in $\mathrm{z}$ direction as it is more important than $\mathrm{x}$ direction in free surface wave modeling. However for this problem, it was observed that using anisotropic mesh causes elongation in flow pattern around the bridge superstructure (if mesh size in $\mathrm{x}$ direction was bigger than mesh size in $\mathrm{z}$ direction). Therefore in all simulation cases mesh used in $\mathrm{x}$ and $\mathrm{z}$ direction are the same size therefore $\mathrm{z}$ direction is not specified in table 1 .

Similar experiments were conducted at University of Florida wave flume. The bridge model tested at University of Florida was a 1:8 scale Escambia Bay Bridge. Vertical force time histories in experiments conducted at the university of Florida wave flume showed some slamming oscillations. Slamming oscillations were attributed to entrapment of air under the bridge superstructure. In experiments conducted at the university of Florida wave flume it was shown that vertical force time history show one oscillation per each cavity (the honeycomb like spaces between bridge deck and girders) as the wave came in contact with the air trapped in the cavity. Slamming oscillations were not witnessed in the force time histories available from Oregon State University experiments. Since the geometry of the bridge was the same in both experiments, it is expected that they trap air in the same fashion. This means the reason for why the experiments conducted at Oregon state university did not show the oscillatory behavior seen in experiments conducted at university of Florida, has to do with the differences in experimental setups used in these two experiments. The experimental setup at Oregon state university was designed to directly measure structural response. The structural response is not necessary the same as the pressure sensor measurements around the bridge superstructure and depends on structure properties such as mass and damping. The experiments conducted at Oregon state university capture high frequency slamming oscillations in the pressure sensor data however such oscillations were not seen in load sensor force time histories. CFD calculates forces by directly integrating pressure around bridge superstructure, therefore in order to compare the simulation results in following sections to experimental data available from Oregon State University, simulation results are filtered using a low pass filter to remove frequencies higher than the ones captured in load sensor force time histories. This will not necessarily affect all force time histories for example horizontal forces did not contain any slamming oscillation therefore filtering did not influence them. Figure 9 
shows the effect of filtering on the vertical force time history of Test 5 for $\mathrm{H}=0.34 \mathrm{~m}$. The shape of filtered force time history is similar to what was observed in experimental data from Oregon State University.

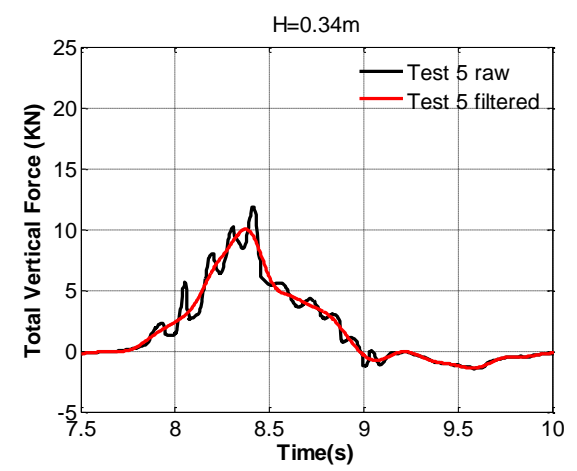

Figure 9. Effect of filtering on force time history of Test $5, \mathrm{H}=0.34 \mathrm{~m}$

\section{D SIMULATION RESULTS}

In this section 2D simulation results are presented for Test 1 and Test 2. In these figures the hollow spheres represent experimental data adapted from Bradner et el. The solid blue and red spheres represent the average of the peak of horizontal and vertical wave forces in simulation respectively. The major difference between Test 1 and 2 in terms of mesh size is the mesh used in bridge region in $\mathrm{x}$ and $\mathrm{z}$ direction which in Test 2 is twice the mesh used in Test 1 . This is done to reduce computational time as in Test 2 the time step used is much smaller than Test 1. In Test 2 the time step size is reduced from $\Delta \mathrm{t}=0.02 \mathrm{~s}$ which is equivalent to $\mathrm{T} / 125$ (where $\mathrm{T}$ is wave period) to $\Delta \mathrm{t}=0.004 \mathrm{~s}$ which is equivalent to T/625. The average of the peak of horizontal and vertical forces for Test 1 and Test 2 are shown in Figure 10 and 11.

Even though the accuracy of prediction of horizontal forces increase when time step size is reduced, overall the accuracy of prediction of vertical forces decreased except for wave height of $\mathrm{H}=0.84 \mathrm{~m}$. Looking into time history of vertical force for $\mathrm{H}=34 \mathrm{~m}$, we see that the behavior of vertical force time history changes when the time step is reduced. Figure 13 shows time history of total vertical force for Test $\# 2(\Delta \mathrm{t}=0.004 \mathrm{~s})$. Comparing to Test \#1 (figure 12) vertical force time history, we understand that reducing time step size from $\Delta \mathrm{t}=0.02 \mathrm{~s}$ to $\Delta \mathrm{t}=0.004 \mathrm{~s}$ causes a highly oscillatory behavior in vertical force time history for some wave heights. This will increase the error in vertical force simulations as seen in figure 11. In figure 12 and 13, horizontal discrete black and blue lines are averages of the peak of vertical force time histories for experiment and simulation respectively.

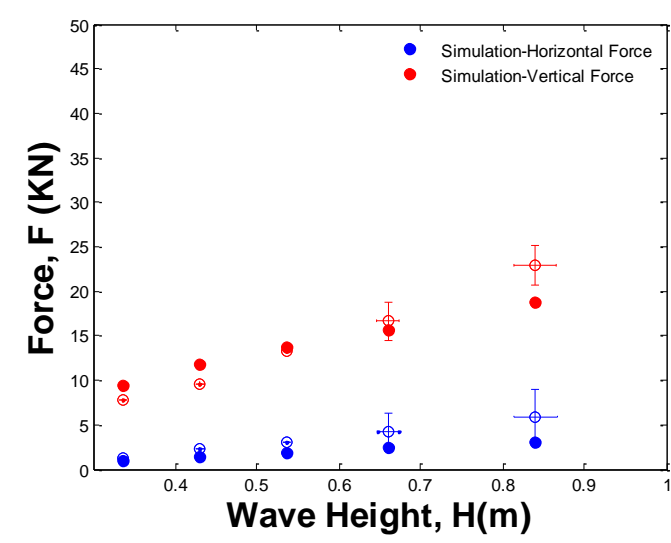

Figure 10. Test 1 simulation results for $d^{*}=0, T=2.5 s$

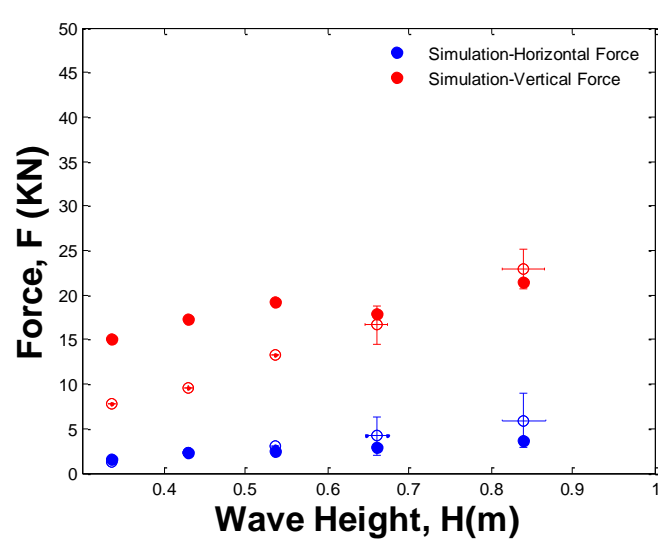

Figure 11. Test 2 simulation results for $\mathrm{d}^{*}=0, \mathrm{~T}=2.5 \mathrm{~s}$

Since reduction of time step reduced the accuracy of vertical force predictions for majority of wave heights. We conclude that the $2 \mathrm{D}$ model is not capable of accurately modeling wave bridge interaction 
because it cannot model the movement of air in transverse direction (y direction) accurately. Symmetry plane used on the side of simulation domain in 2D model (shown in figure 7) would not allow the air to escape in a timely manner which causes excessive oscillation in vertical force time histories when time step is reduced. This oscillatory behavior as a result of air entrapment was already captured in experiments conducted at University of Florida and as discussed is related to entrapment of air in cavities between bridge girder and diaphragm.

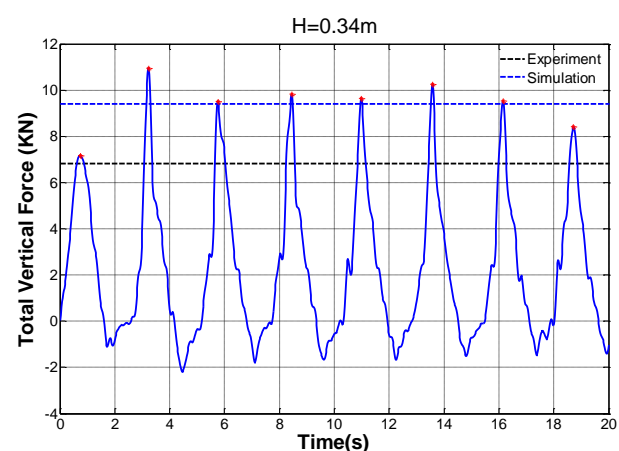

Figure 12. Test 1 quasi steady vertical force time history for $\mathrm{H}=0.34 \mathrm{~m}, \mathrm{~d}^{\star}=0, \mathrm{~T}=2.5 \mathrm{~s}$

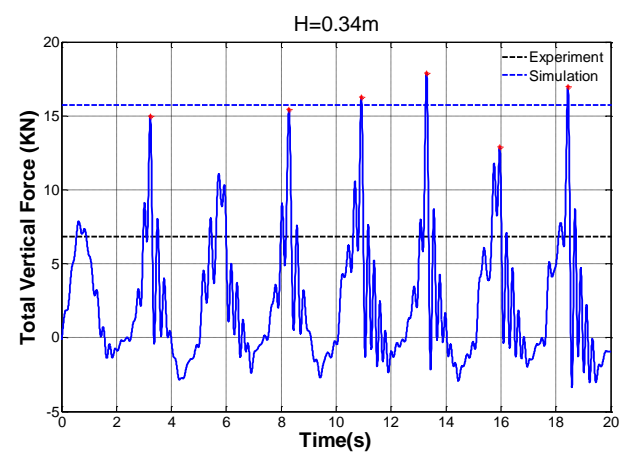

Figure 13. Test 2 simulation results for $\mathrm{H}=0.34 \mathrm{~m}, \mathrm{~d}^{\star}=0, \mathrm{~T}=2.5 \mathrm{~s}$

In order to more accurately model the air movement under the bridge superstructure and to see the effect of full 3D modeling on accuracy of hydrodynamic force predictions, in the next section the bridge superstructure is modeled in full $3 \mathrm{D}$.

\section{D SIMULATION RESULTS}

Figure 14 shows the boundary conditions used in 3D simulation cases. The range of mesh sizes and time steps investigated are shown in table 1. Compared to 2D cases since the computer resources were limited in meshing the simulation domain, we coarsened the mesh in the deep water region since in $2 \mathrm{D}$ simulations we witnessed that the velocity vectors close to bottom boundary were small and therefore the bottom boundary influence on horizontal and vertical forces applied to bridge super structure were minimal.

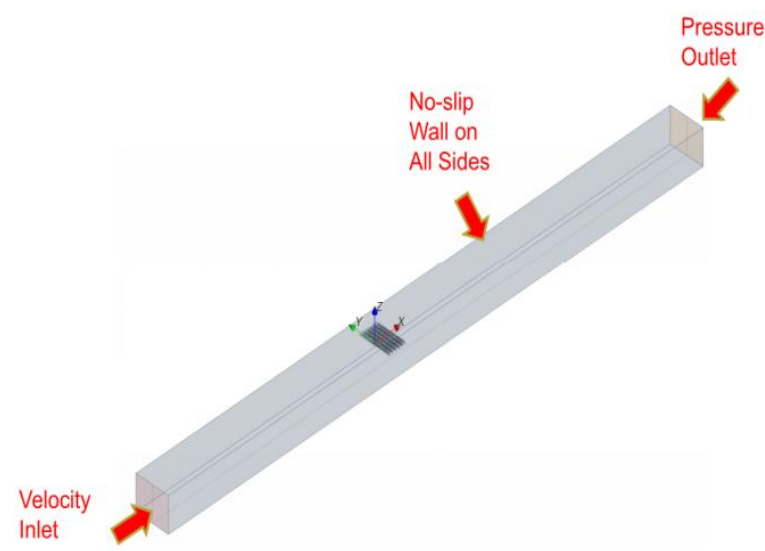

Figure 14. Boundary conditions used in 3D simulations

3D models require the mesh size to be specified in transverse direction (y direction). As it will be shown the size of mesh used in transverse direction influences the modeling of the air movement between bridge girders and diaphragms which greatly influence the vertical force time history. 3D meshed bridge is shown in figure 15 . In order to reduce the number of mesh used in the simulation domain a symmetry plane was considered in the middle width of bridge superstructure. This means in all 3D simulation cases only half the bridge was modeled. The number of mesh shown in table 1 also shows half the mesh required to model the full bridge superstructure. The average of the peak of 
horizontal and vertical forces for Test 3 and 4 are shown in figures 16 and 17. 3D Test 3 results are comparable to 2D Test 1 results since they have the same time step size. Even though the mesh used in Test 3 in $\mathrm{x}$ and $\mathrm{z}$ direction is twice the mesh used in Test 1 in free surface region, Test 3 seems to do a better job of predicting horizontal forces.
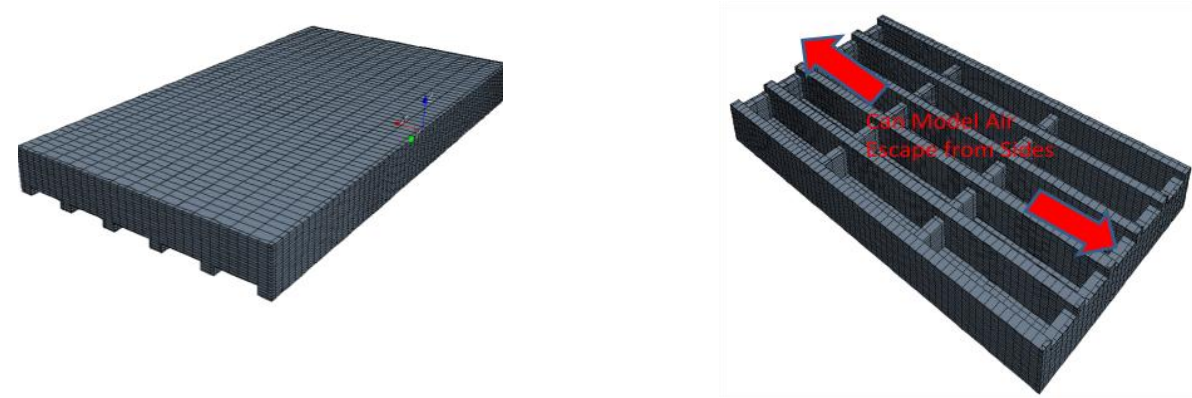

Figure 15. Meshed bridge in 3D

However it seems that Test 3 is not significantly better than Test 1 in terms of predicting vertical forces. This is probably because at $\Delta \mathrm{t}=\mathrm{T} / 125 \mathrm{~s}$, the model does not capture the effect of air entrapment at all. Hence a $3 \mathrm{D}$ model with a coarser mesh is not able to predict vertical forces with a better accuracy than 2D model. Test 4 uses exactly the same mesh as Test 3 but the time step size is reduced to $\Delta \mathrm{t}=\mathrm{T} / 625 \mathrm{~s}$. Comparing figure 16 to 17 we see that the reduction of time step improved the overall accuracy in horizontal force predictions. However For vertical forces, again reduction of time step size to $\Delta \mathrm{t}=\mathrm{T} / 625 \mathrm{~s}$ caused excessive oscillatory behavior which resulted in over prediction of vertical forces for $\mathrm{H}=0.34 \mathrm{~m}, \mathrm{H}=0.43 \mathrm{~m}$, and $\mathrm{H}=0.54 \mathrm{~m}$. However the magnitude of these oscillations is smaller than oscillations witnessed in 2D Test 2. This means some air was able to move out therefore we witnessed oscillations with smaller amplitude. The mesh used in transverse direction was not fine enough to allow the air to move out in a timely manner. As we see, the accuracy of vertical force predictions are improved for $\mathrm{H}=0.66 \mathrm{~m}$ and $\mathrm{H}=0.84 \mathrm{~m}$.

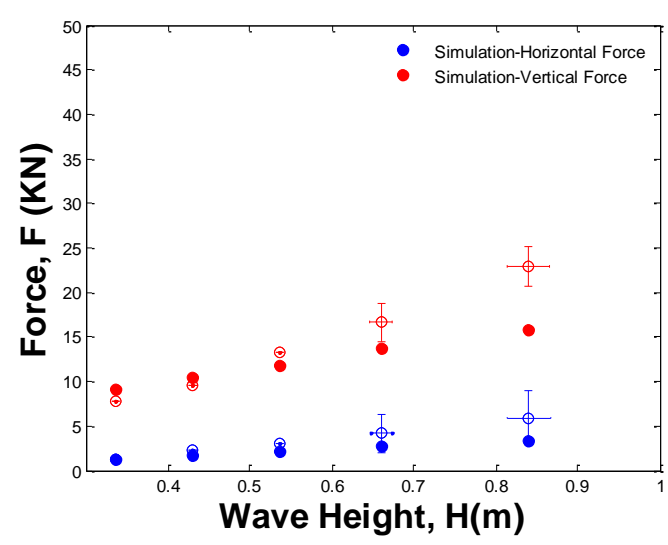

Figure 16. Test 3 simulation results for $d^{*}=0, T=2.5 \mathrm{~s}$

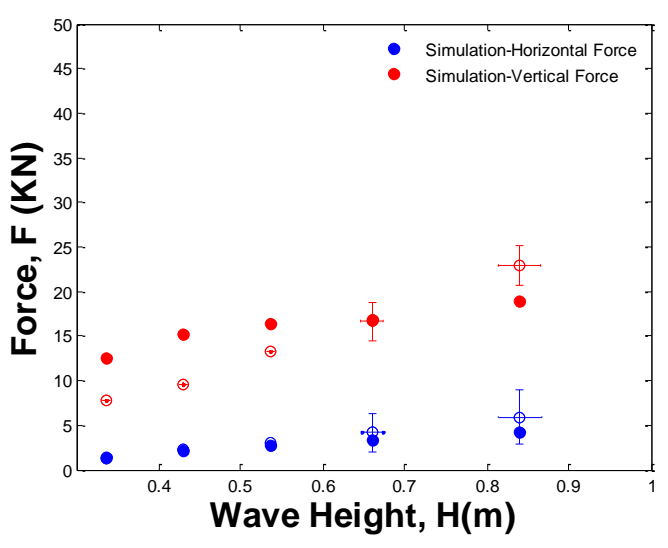

Figure 17. Test 4 simulation results for $d^{*}=0, T=2.5 s$

In Test 5 the mesh size in bridge region is cut into half in all three directions while the time step size is kept the same as Test 4. Also in free surface region the mesh used in $\mathrm{x}$ and $\mathrm{z}$ direction is cut into half while the mesh in y direction was kept the same as Test 4 . The mesh in deep water region was also kept the same as Test 4. As we see the reduction of mesh size in bridge region and free surface region increased the total number of mesh used in simulation domain from 2,834,678 to 11,483,096. As we see in Test 5 the quasi steady vertical force time history for $\mathrm{H}=0.34 \mathrm{~m}$ (figure 18) does not show the slamming oscillations witnessed in Test 4 and Test 2 (figure 12). Figure 19 shows the comparison between averages of the peak of forces for Test 5 to experimental data. Compared to Test 4 results, overall Test 5 simulation results for total horizontal forces applied to bridge superstructure are slightly less accurate. The mesh used in Test 5 in free surface region in $\mathrm{x}$ and $\mathrm{z}$ direction is half the mesh that is 
used in Test 4. However due to limitation in computer resources, the mesh in y direction in free surface was kept the same as Test 4 . This will increase the mesh aspect ratio in Test 5 in free surface region. The mesh aspect ratio increased from 2.4 (in Test 4) to 4.8 (in Test 5). This is likely the reason for why the predictions for horizontal forces in Test 5 became slightly less accurate.

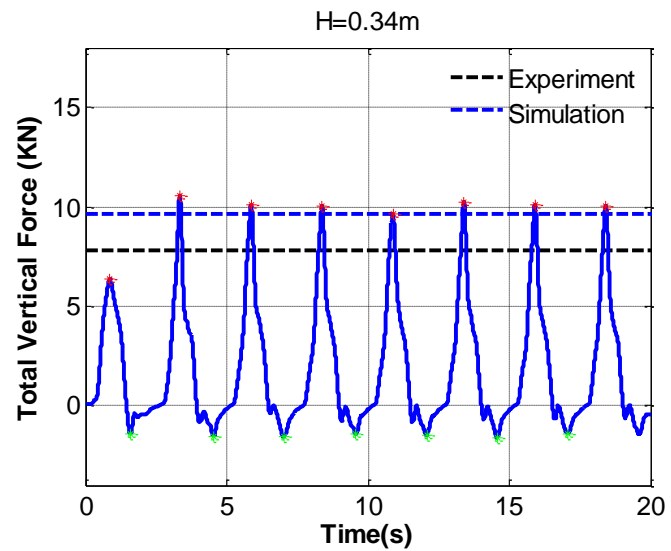

Figure 18. Test 5 quasi steady vertical force time history for $\mathrm{H}=0.34 \mathrm{~m}, \mathrm{~d}^{*}=0, \mathrm{~T}=2.5 \mathrm{~s}$

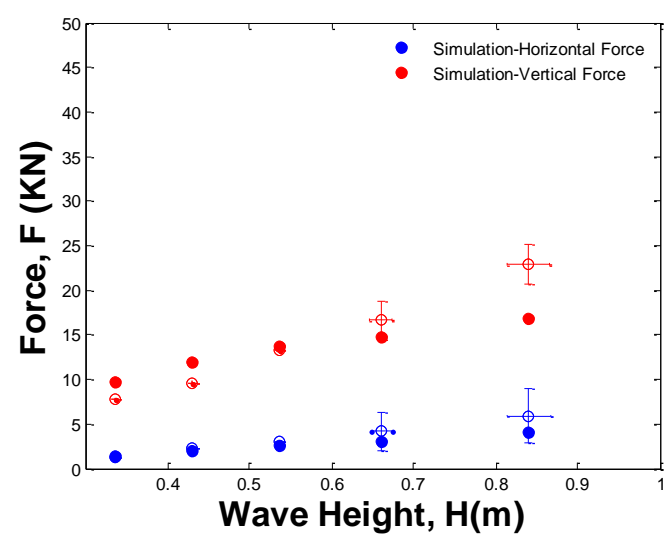

Figure 19. Test 5 simulation results for $d^{*}=0, T=2.5 s$

Since mesh size and time step affect simulation results for each wave height in a different manner in order to compare all simulation cases with each other in terms of quality of simulation, we calculate maximum error and normalized root mean square error for both horizontal and vertical force for all wave heights and test cases. These data are shown in table 2 for each test case. The best simulation is a simulation in which normalized root mean square error (nrms) and maximum error in horizontal and vertical forces are reasonably small.

Test $F_{x}$, nrms \% $\quad F_{z}$, nrms \% Max \%error in $F_{x} \quad$ Max \%error in $F_{y}$

\begin{tabular}{lllll}
\hline 1 & 35 & 15 & 48 & 23 \\
2 & 25 & 36 & 37 & 92 \\
3 & 31 & 24 & 44 & 31 \\
4 & 18 & 26 & 27 & 60 \\
5 & 22 & 21 & 32 & 26
\end{tabular}

Table 2. Error for different simulation test cases for $d^{\star}=0, T=2.5 s$

As expected, Test 5 provided the most accurate simulation results compared to all other test cases because it was able to predict both horizontal and vertical forces with reasonable accuracy (nrms $<22 \%$ ) and the maximum error was less than $32 \%$. In addition to positive forces, we can also compare the negative forces to experimental data. Negative horizontal force is the force in the direction opposite to wave propagation direction and negative vertical force is a downward force. Figure 20 and 21 show the comparison between positive and negative horizontal and vertical forces to experimental data for Test 5. Negative horizontal and vertical forces compare remarkably well to experimental data.

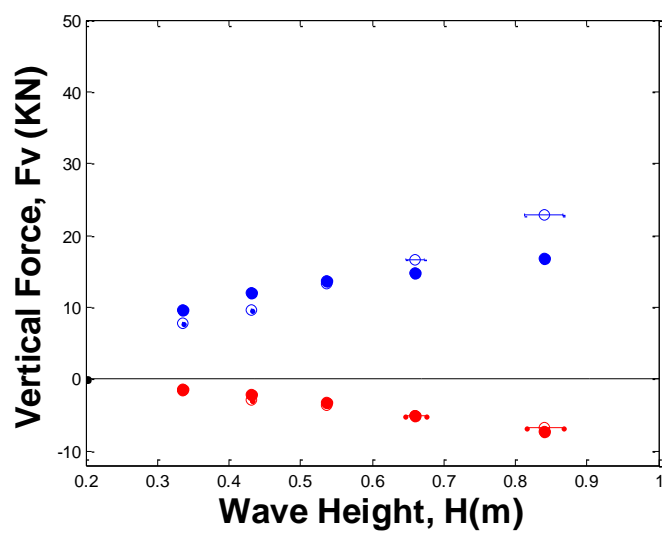

Figure 20. Test 5 positive and negative vertical forces for $d^{\star}=0, T=2.5 s$

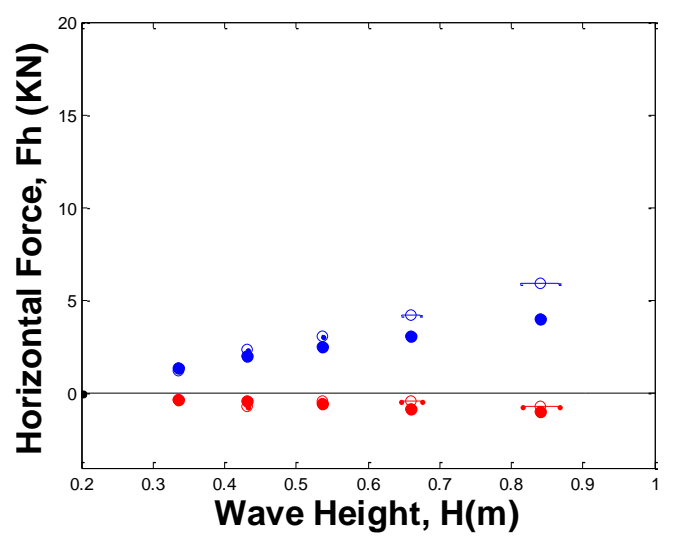

Figure 21. Test 5 positive and negative vertical forces for $d^{*}=0, T=2.5 s$ 
Figure 22 shows pressure contour scenes and figure 23 shows the 3D iso surface scenes of interaction of one wave with height of $\mathrm{H}=0.84 \mathrm{~m}$ with bridge superstructure during one wave period for Test 5 .
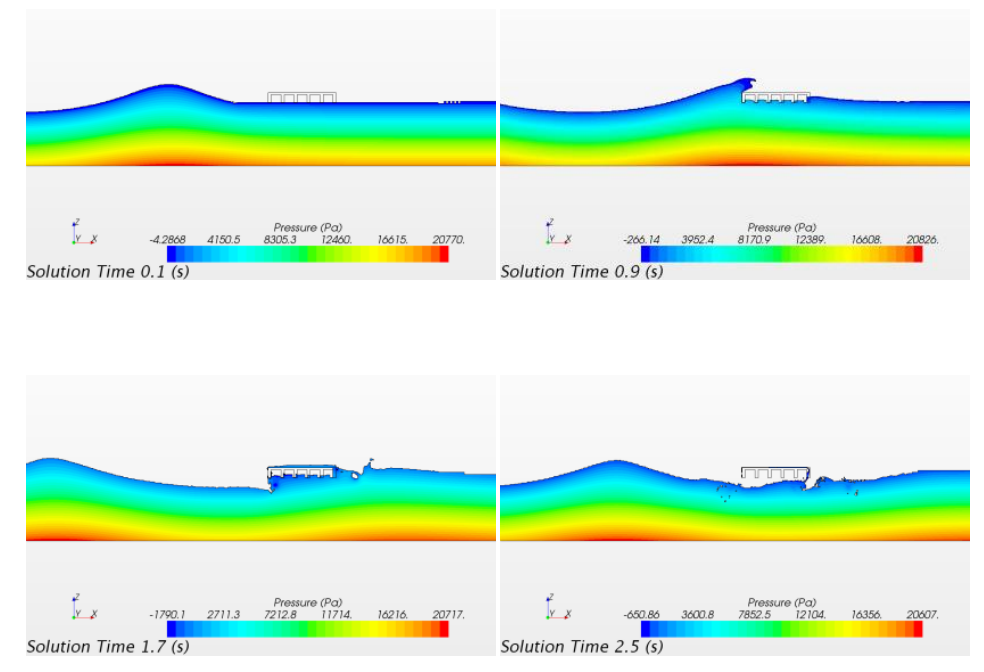

Figure 22. Test 5 pressure contour scenes for $\mathrm{H}=0.84 \mathrm{~m}, \mathrm{~d}^{*}=0, \mathrm{~T}=2.5 \mathrm{~s}$
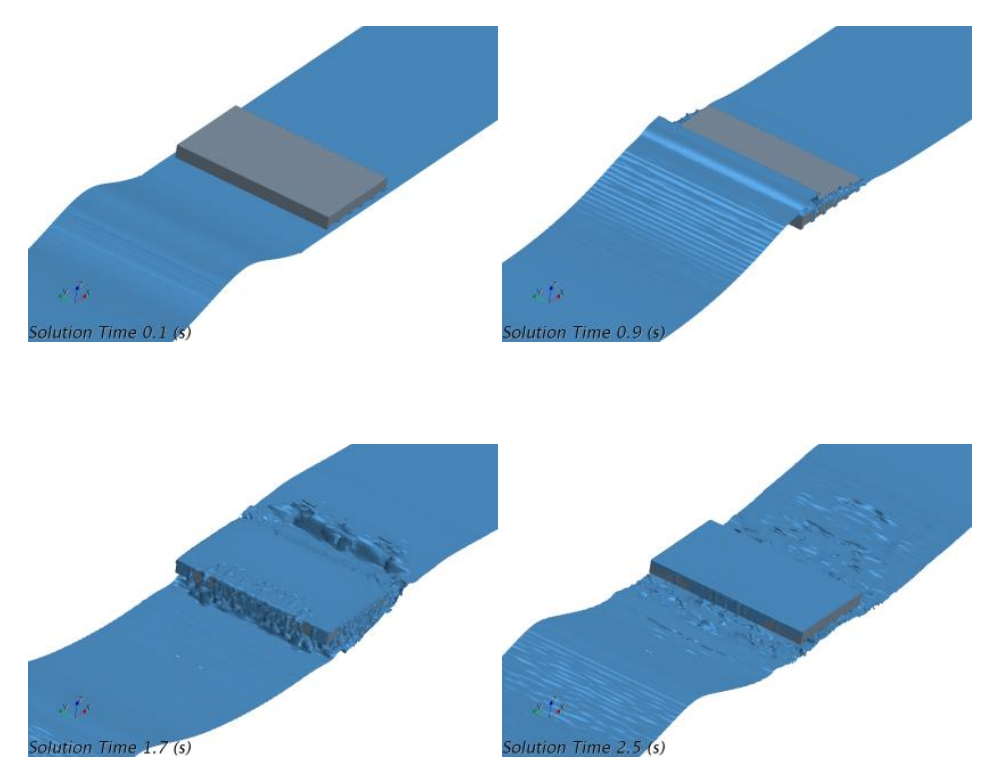

Figure 23. Test 5 3D iso surface scene for $\mathrm{H}=0.84 \mathrm{~m}, \mathrm{~d}^{*}=0, \mathrm{~T}=2.5 \mathrm{~s}$

Looking at the data in table 2 we can draw the following important conclusions regarding the effect of mesh size and time step on total horizontal and vertical forces applied to bridge superstructure:

1. Reduction of time step from $\Delta \mathrm{t}=\mathrm{T} / 125 \mathrm{~s}$ to $\Delta \mathrm{t}=\mathrm{T} / 625 \mathrm{~s}$ always improved the prediction of horizontal forces applied to bridge superstructure no matter what kind of mesh or model (2D or 3D) was used.

2. In similar conditions (same mesh and time step size), 3D model always predicted better results for horizontal force compared to $2 \mathrm{D}$ model. 
3. When the time step is reduced to $\Delta \mathrm{t}=\mathrm{T} / 625 \mathrm{~s}$ the model started to capture slamming oscillations. The accuracy of prediction of these slamming oscillations was directly related to how accurately the air movement under the bridge superstructure was modeled. For example since 2D model did not let the air move in transverse direction, it could not predict the vertical force with reasonable accuracy when time step is reduced to $\Delta \mathrm{t}=\mathrm{T} / 625 \mathrm{~s}$ as seen in Test 2. Also if the mesh used in bridge region in transverse direction is not fine enough the simulation will show excessive oscillation as shown in Test 4.

4. In this research the best result was obtained in 3D model with time step size of $\Delta \mathrm{t}=\mathrm{T} / 625 \mathrm{~s}$ and the following mesh sizes in different simulation regions as a function of wave length $\lambda$ :

\begin{tabular}{lcc} 
Region & $\begin{array}{c}\text { Mesh size in } \mathbf{x} \text { and } \\
\mathbf{z} \text { direction }\end{array}$ & $\begin{array}{c}\text { Mesh size in } \mathbf{y} \\
\text { direction }\end{array}$ \\
\hline Bridge & $\lambda / 1305$ & $\lambda / 326$ \\
Free surface & $\lambda / 391$ & $\lambda / 82$ \\
Deep water & $\lambda / 98$ & $\lambda / 41$
\end{tabular}

Table 2. Mesh used in different regions for Test 5 ( is calculated for $\mathrm{H}=0.84 \mathrm{~m}$ )

Not only quasi-steady forces predicted by Test 5 setup compared reasonably well to quasi-steady forces captured in experimental data, but also the shape of slamming forces captured in Test 5 simulation results show a similar pattern to what was captured in simulations conducted at university of Florida wave flume with number of slamming oscillations being equal to number of cavities under the bridge superstructure. The shape of raw (unfiltered) vertical force time history for different test cases is shown in figure 19. As it is evident in this figure only the test cases where time step was at $\Delta \mathrm{t}=\mathrm{T} / 625 \mathrm{~s}$ show the slamming oscillation (Test $2,4,5$ ). The magnitude of slamming oscillation was biggest for Test 2 where the air was not allowed to exit from sides therefore heavily compressed. The magnitude of slamming force was smallest for Test 5 which had the finest mesh in transverse direction therefore allowed the air to escape in a timely manner.

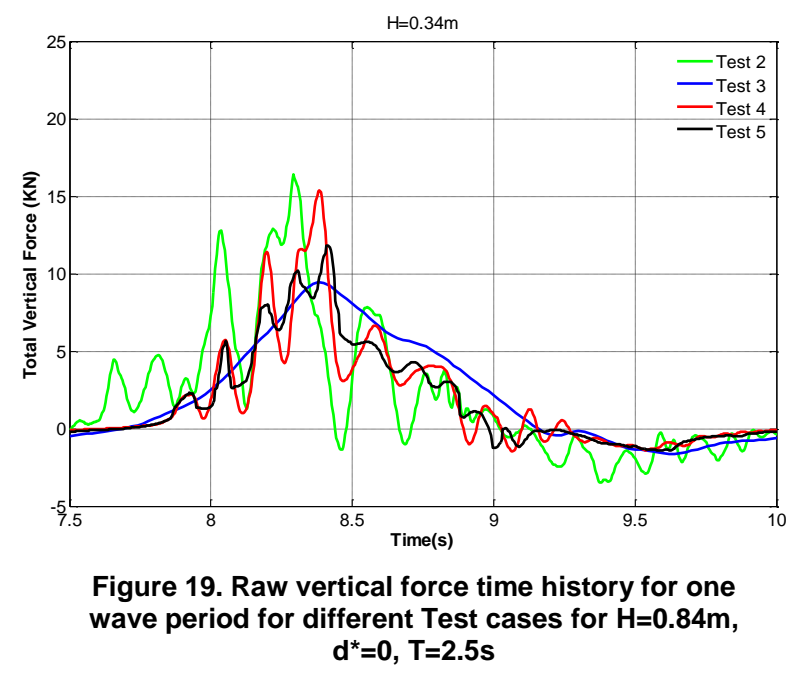

5. In addition to the mesh size, mesh aspect ratio also influence the accuracy of simulation results. For the best result based on investigated test cases, it is recommended to keep the mesh aspect ratio bellow 3 . 


\section{Conclusion}

The numerical wave-load model based on Navier Stokes type equations and the VOF method has been applied to investigate the dynamic impact of wave forces on a 1:5 scale Escambia Bay Bridge which was damaged during Hurricane Ivan. Simulations were conducted using 2D and 3D model for various wave heights ranging from $\mathrm{H}=0.34 \mathrm{~m}$ to $\mathrm{H}=0.84 \mathrm{~m}$ with wave period of $\mathrm{T}=2.5 \mathrm{~s}$ interacting with bridge superstructure for $20 \mathrm{~s}$. Simulation results were compared to experimental data available from Hinsdale wave laboratory at Oregon State University.

It was determined that the simulation results of wave-bridge interaction using two phase Navier Stokes equation were very sensitive to the choice of mesh size and time step. Several 2D and 3D cases with different mesh size and time steps were investigated. The shape of vertical force time history changed from smooth to highly oscillatory as time step reduced from $\Delta \mathrm{t}=\mathrm{T} / 125 \mathrm{~s}$ to $\Delta \mathrm{t}=\mathrm{T} / 625 \mathrm{~s}$ for some wave heights in both $2 \mathrm{D}$ and $3 \mathrm{D}$ model. It has been determined that the main reason for this oscillatory behavior in vertical force time history was the entrapment of air under the bridge superstructure. Therefore the accuracy of vertical forces highly depends on how accurate the air movement between bridge girders and diaphragms was modeled. Obviously, since 2D model was not able to model the movement of air in transverse direction was not able to capture quasi-steady and slamming vertical forces accurately. In addition, it was shown that the 3D model with the mesh size in bridge region which was not fine enough, behaved similar to 2D model showing excessive oscillation in vertical force time histories. With proper mesh size and time step it was possible to predict horizontal and vertical forces for wave heights ranging from $\mathrm{H}=0.34 \mathrm{~m}$ to $\mathrm{H}=0.84 \mathrm{~m}$ with reasonable accuracy (maximum error in horizontal force 32 percent and in vertical force 26 percent).

In addition, since the experiments conducted at University of Florida showed the slamming oscillations in vertical force time history but the experiments conducted in Oregon State University did not show these slamming oscillations we can conclude that as structure's mass increase chances of it responding to high frequency slamming oscillations becomes smaller. This means engineers who are using results of CFD simulations for wave bridge interaction should use their judgment about considering high frequency slamming oscillation in their design because as experiment showed these slamming oscillations were not registered at bridge support therefore the bridge superstructure did not respond to this high frequency external force.

\section{REFERENCES}

AASHTO. (2008). Final Draft: Guide Specifications for Bridges Vulnerable to Coastal Storms (BVCS1). Washington, DC: American Association of State Highway and Transportation Officials.

Bozorgnia, M., Lee, Jiin Jen, 2010. "Wave Structure Interaction: Role of Entrapped Air on Wave Impact and Uplift Forces.” Proceedings of International Conference on Coastal Engineering 2010, Shanghai, China.

Bradner, C. 2008. Large scale laboratory observations of wave forces on highway bridge super structure. Master Thesis Submitted to Oregon State University.

Cuomo, G., Allsop, W., and McConnell, K. 2003. "Dynamic wave loads on coastal structures: Analysis of impulsive and pulsating wave loads." Coastal Structures 2003-Proc., Conf., Portland, Ore., ASCE, 356-368.

Denson, K. H. 1978. "Wave forces on causeway-type coastal bridges." Water Resources Research Institute, Mississippi State Univ., Mississippi State, Miss.

Douglass, S. L., Chen, Q., and Olsen, J. M. 2006. "Wave forces on bridge decks." Coastal Transportation Engineering Research and Education Center, Univ. of South Alabama, Mobile, Ala.

Douglass, S. L., Hughes, S., Rogers, S., and Chen, Q. 2004. "The impact of Hurricane Ivan to the coastal roads in Florida and Alabama: A preliminary report." Rep. to Coastal Transportation Engineering Research and Education Center, Univ. of South Alabama, Mobile, Ala.

Ferziger, J.H. \& Peric, M., Computational Methods for Fluid Dynamics, Springer, Berlin, 1996.

French, J. A. 1969. "Wave uplift pressure on horizontal platforms." Rep. No. KHR19, W. M. Keck Laboratory of Hydraulics and Water Resources, California Inst. of Technology, Pasadena, Calif.

Hirt, C. W., and Nichols, B. D. 1981. "Volume of fluid VOF method for the dynamics of free boundaries.” J. Comput. Phys., 391, 201-225.

Huang, W., and Hong Xiao, 2009. Numerical Modeling of Dynamic Wave Force Acting on Escambia Bay Bridge Deck during Hurricane Ivan, Journal of Waterway, Port, Coastal and Ocean Engineering, ASCE, Volume 135, Issue 4, pp. 164-175. 
Kaplan, P., Murray, J. J., and Yu, W. C. 1995. "Theoretical analysis of wave impact forces on platform deck structures." Proc., Int. Conf. on Offshore Mechanics and Arctic Engineering, Copenhagen, Denmark, 1A, ASME, New York, 189-198.

STAR CCM+ software manual, CD-adapco, 2010. 